\title{
Pediatric RSV infection during two winter seasons in British Columbia: A role for subgroup analysis in young children?
}

\author{
E WILSON, MD, C ORVELL, MD, PHD, B MORRISON, PHD, E ThOMAS, MD, PHD
}

\begin{abstract}
Using a panel of eight monoclonal antibodies directed against the G, F and NP proteins of respiratory syncytial virus, 167 virus isolates from nasopharyngeal washing cultures at British Columbia Children's Hospital during two consecutive epidemics were subgrouped. Slides made and frozen at the time of virus isolation or prepared from recovered frozen passage material, were assayed by indirect immunofluorescence. Of 85 strains tested in 1987-88, 54 (64\%) were subgroup A, and 31 (36\%) subgroup B. By contrast, of
\end{abstract}

82 strains tested in 1988-89 five $(6 \%)$ were subgroup A and $77(94 \%)$ subgroup B. Review of patient charts did not reveal significant differences in clinical course of patients infected with the two subgroups, but the risk of infection with subgroup A was significantly greater than the risk of subgroup $B$ infection in younger patients. Can J Infect Dis 1990;1(4):112-116

Key Words: Paramyxovirus infections, Respiratory syncytial viruses, Respiratory tract infections
$\mathrm{R}$ ESPIRATORY SYNCYTLAL VIRUS (RSV) IS A MAJOR cause of upper and lower respiratory tract infections in the pediatric patient population. Studies of RSV pathogenesis and epidemiology are becoming increasingly important due to the introduction of antiviral agents such as ribavirin for treatment of severe RSV infections in infants and young children. The development of monoclonal antibodies to RSV has permitted identification of two major subgroups (A and B) (1-3). Retro-

Departments of Pathology. Pediatrics and Epidemiology. Faculty of Medicine, University of British Columbia and British Columbia Children's Hospital, Vancouver, British Columbia; and Departments of Virology. National Bacteriological Laboratory and Karolinski Institute. Stockholm, Sweden

Correspondence and reprints: Dr E Thomas, British Columbia Children's Hospital, 4480 Oak Street, Vancouver. British Columbia V6H 3V4. Telephone (604) 875-2345 ext 7458

Received for publication June 23, 1990. Accepted September 26. 1990 spective studies on stored laboratory isolates in centres in Europe and the United States have shown that both subgroups circulate in the community and are usually both present in any one epidemic (4-8). Heterogeneity within both subgroups has been described $(9,10)$, but the broad division is still accepted. What is less clear from studies so far is whether there is a difference in virulence between the subgroups. Tayler and colleagues in Newcastle (11) found that type A occurred in younger infants and illness was more severe, judging by the need for respiratory and nutritional support. No such difference was seen in a five year study in West Virginia (4). The purpose of the present study was to elucidate the local epidemiology of RSV infection in British Columbia. Using monoclonal antibodies directed against the major structural proteins of RSV (glycoprotein [G], fusion protein $[F]$ and nucleoprotein [NP]) and indirect immunofluorescence, $167 \mathrm{RSV}$ isolates from pediatric patients 
during two consecutive epidemics were subtyped and a limited retrospective chart review performed to document disease severity.

\section{MATERIALS AND METHODS}

Specimen collection: Nasopharyngeal washings were obtained by the instillation and immediate recovery of 0.5 to $1 \mathrm{~mL}$ of sterile saline through a baby feeding catheter, which was inserted into the nasopharynx via one nostril. Specimens were transferred to a sterile container which was immediately brought to the laboratory for culture by hand ( 5 mins transportation time).

Cells: Primary Rhesus monkey kidney cells (Connaught Diagnostics) were maintained in Eagle's minimum essential medium, supplemented with $100 \mathrm{iu}$ of penicillin and $100 \mu \mathrm{g}$ of streptomycin per $\mathrm{mL}$. HEp-2-epidermoid carcinoma cells and MRC5-human lung diploid fibroblasts (Bartels Immunodiagnostic Supplies, Washington) were maintained in Eagle's minimum essential medium as above with the addition of fetal calf serum concentrations of 1 and 3\%, respectively.

Virus culture and preparation of slides: One millilitre of the fresh specimen was added to two tubes of each cell type and incubated at $35^{\circ} \mathrm{C}$ overnight on a stationary rack. After 16 to $20 \mathrm{~h}$ incubation, the medium was changed and the cultures transferred to a roller drum where they were maintained for 14 days. RSV was detected by its typical cytopathic effect, which was noted on average five to 10 days post inoculation, and at this time cells were washed and scraped down in buffered phosphate saline. A drop of cell suspension was added to each well of a 10 well microscopy slide, which was air dried and fixed in acetone. Slides were stored at $-70^{\circ} \mathrm{C}$ until used. For the 1987-88 season, slides were made in conjunction with a positive culture result. For the 1988-89 season, virus was recovered from reculturing the first passage of the original positive culture and subsequent immunofluorescence assay slide preparation.

Monoclonal antibodies and immunofluorescence assay: The monoclonal antibodies used were prepared against a member of subgroup B, RS WV4843, and characterized as previously described $(12,13)$. They represented specificities for the glycoprotein $\mathrm{G}$, fusion glycoprotein $\mathrm{F}$ and the NP protein. Their known epitope specificities and reactivities for subgroups A and B are shown in Table 1. The monoclonal antibodies were stored at $-70^{\circ} \mathrm{C}$ in aliquots and thawed just prior to use. For immunofluorescence assay, each of eight wells on a 10 well slide was incubated for 20 mins at $37^{\circ} \mathrm{C}$ with $20 \mu \mathrm{L}$ of monoclonal antibodies diluted 1 in 20 in buffered phosphate saline with $1 \%$
TABLE 1

Monoclonal antibody reactivity of respiratory syncytial virus subgroups $A$ and $B$

\begin{tabular}{lccc}
\hline $\begin{array}{l}\text { MAb } \\
\text { (Clone no) }\end{array}$ & Specificity & \multicolumn{2}{c}{ Reactivity against } \\
Subgroup A & Subgroup B \\
\hline 9.273 & Gl* & - & + \\
$8.25 ?$ & NP1 & + & + \\
8.188 & G1 & - & + \\
8.296 & NP2 & + & + \\
9.351 & NP3 & + & + \\
9.250 & F3 & + & + \\
8.305 & G1 & - & + \\
7.858 & Fl & - & + \\
\hline
\end{tabular}

*The number behind the letter represents a particular epitope of the protein. MAb Monoclonal antibody; $G$ Glycoprotein $G ; N P$ Nucleoprotein NP: F Fusion protein F

bovine serum albumin (Sigma Chemical Co, Missouri). The slide was rinsed in buffered phosphate saline; a fluorescein isothiocyanate-conjugated rabbit antimouse IgG antibody (H\&L) (BioCan Scientific Inc) was used as the second antibody at a 1 in 40 dilution using buffered phosphate saline plus $1 \%$ bovine serum albumin. The slides were washed with buffered phosphate saline, air dried, mounted and assessed by the same observer using a Leitz Laborlux 12 microscope with a mercury short arc lamp. Fluorescence was graded '0' to '4+'; greater than ' $1+$ ' being considered positive.

Patients and specimens: Eighty-five positive RSV isolates from the winter of 1987-88 and 82 isolates from the winter of 1988-89 were studied. The majority of patients had bronchiolitis; a few had pneumonia; and all were admitted. Most patients were from Vancouver (population 451,700) or its surrounding municipalities (population $1,440,000)$. A few sick children were airlifted in from other hospitals throughout the province of British Columbia (population 3,055,600).

Chart review and statistical analysis: A retrospective, limited, chart review through health records (blinded to subgrouping) was performed for the 85 patients from the $1987-88$ season. The following parameters were noted: requirement of supplemental oxygen; pneumonia on chest x-ray; ventilation required; and ribavirin therapy. Sixteen patients with underlying cardiac, respiratory or neuromuscular disease and immune compromised patients were excluded. A total of 69 patients were studied ( 45 with subgroup A, and 24 with subgroup B).

Pearson's $\chi^{2}$ test was used for assessing the difference in sex ratio and the difference in the proportion with severe disease (two or more of the following parameters applied: supplemental oxygen; pneumonia on chest $\mathrm{x}$-ray; ventilation required; ribavirin therapy) between the two sub- 


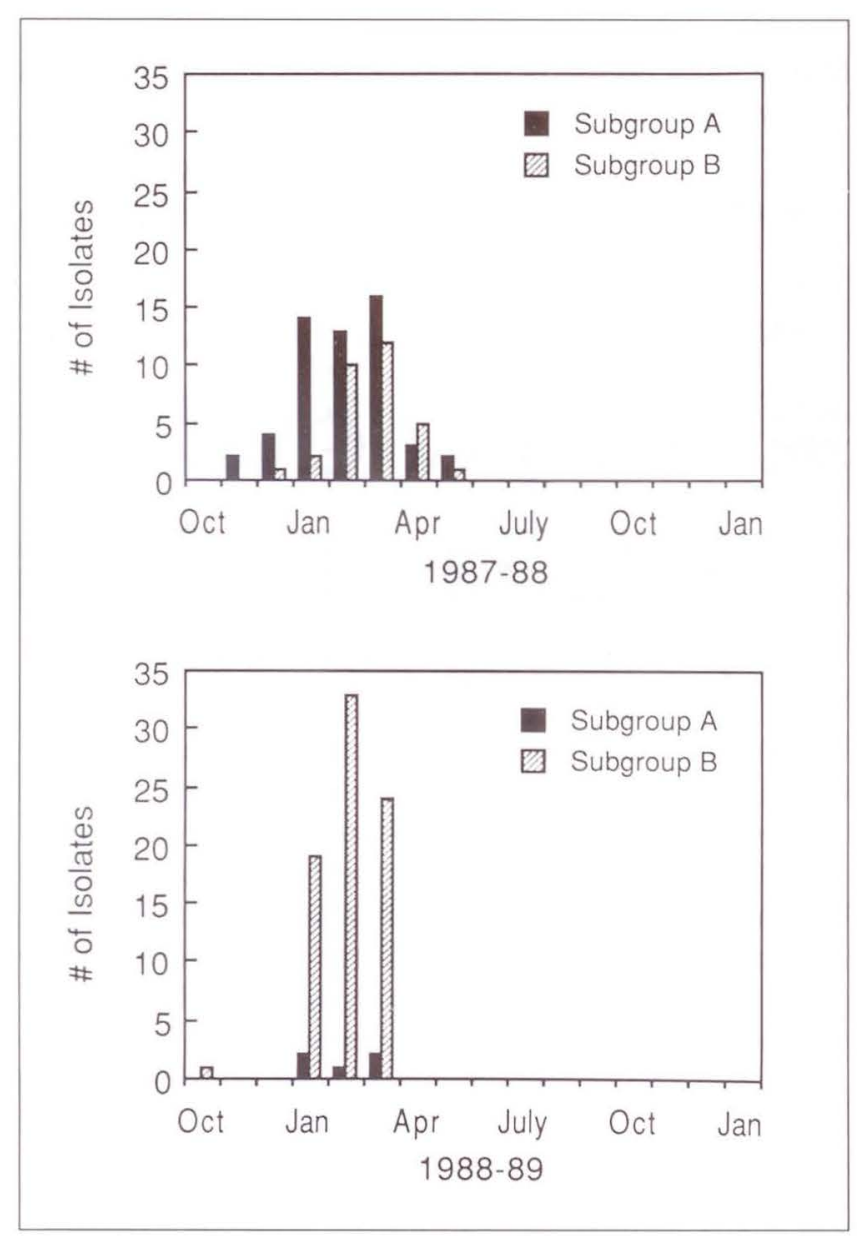

Figure 1) RSV subgroup isolates (y-axis) are plotted against the time when the specimen was obtained ( $x$ axis) for subgroups $A$ and $B$. respectively

groups using the data from the 1987-88 season. The data for both seasons were pooled and the median test employed to compare the age and length of stay distributions for the two RSV subgroups.

\section{RESULTS}

The two seasons studied showed differing RSV subgroup prevalences. In 1987-88, of 85 isolates tested, 54 (64\%) were subgroup A and 31 (36\%) subgroup B. In contrast, during the winter of $1988-89,77$ of 82 isolates subgrouped (94\%) were subgroup B and five of $82(6 \%)$ subgroup A (Figure 1). During both seasons, there were more male children affected: $1987-88,49$ of 85 male (58\%), 36 of 85 female $(42 \%)$; 1988-89, 55 of 82 male (67\%), 27 of 82 female (33\%); but there was no significant difference in the sex ratio between the subgroups $\left(\chi_{1}^{2}=1.33, \mathrm{P}=0.25\right)$.

The seasonal variations of subgroups by month are shown in Figures 1 and 2. The peak risk was in January to March for both subgroups. Subgroups for both seasons are plotted against age in

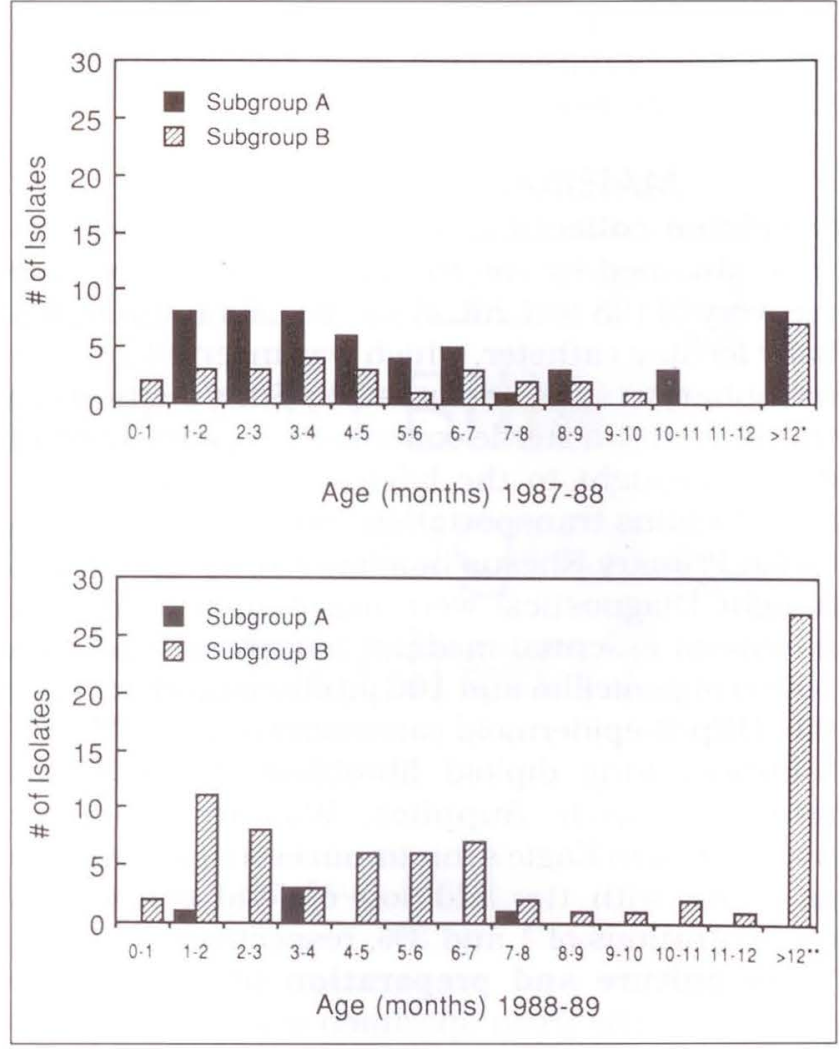

Figure 2) Numbers of positive RSV isolates (y-axis) are plotted against age ( $x$-axis) for two seasons. *Median age 19 months; **Median age 26 months

Figure 2, and 70 of 85 patients $(82 \%)$ were younger than one year during the 1987-88 season, and 55 of $82(67 \%)$ were younger than one year during the 1988-89 season.

During both seasons, there was a relative sparing of one-month-old infants and only one patient during the two seasons younger than one month (three weeks) (Figure 2). Seventeen per cent of the cases in 1987-88 were older than one year, and are all represented in one bar per subgroup. The age range in this group was 12 months to 18 years with a median age of 19 months. Thirty-three per cent of patients during 1988-89 were older than one year (range 12 months to 9.5 years). These are all represented in one bar, with a median age of 26 months in Figure 2. There was a significant difference between attack rate of the two subtypes with regard to age, with subgroup A infecting a significantly larger number of young children than subgroup B $\left(\chi_{1}^{2}=3.91, P=0.048\right)$ (Figure 2).

Further analysis of the results for 1987-88 only was made by a retrospective, limited review of patient charts in an attempt to detect any obvious differences in illness severity according to subgroup. When the requirements for two or more of the following parameters were compared (supplemental oxygen, ventilation and ribavirin 
therapy, duration of hospital stay and presence of pneumonia on chest $\mathrm{x}$-ray), there were no significant differences $\left(\chi_{1}^{2}=0.65, \mathrm{P}=0.80\right)$ between subgroups $\mathrm{A}$ and $\mathrm{B}$.

The mean durations of hospital stay in 1987-88 for patients infected with subgroup A $(4.5 \pm 4.3$ days) and $\mathrm{B}(3.3 \pm 1.8$ days) isolates without underlying disease were not significantly different $\left(\chi_{1}^{2}=0.449, \mathrm{P}=0.503\right)$.

\section{DISCUSSION}

RSV infection is a major cause of hospitalization of infants and young children in the Western world (14) and imposes a substantial burden on hospital beds and isolation resources during each winter-spring epidemic. The risk of severe RSV infection is dependent on a multitude of factors including age, host immunity and underlying respiratory or cardiac disease, as well as route and duration of exposure (15).

A common diagnostic method for RSV disease is direct detection of the antigen by ELISA or immunofluorescence assay (15). The commercially available direct detection assays use type common antibodies which do not allow distinction of subgroups $\mathrm{A}$ and $\mathrm{B}$. With the introduction of monoclonal antibodies to a variety of RSV proteins, a new tool was provided for the study of this important virus. Is subgrouping of the virus by monoclonal antibodies only of value in epidemiology and basic virology studies or can it be used effectively to help with infection control policies and/or as a clinical predictor? In order to be of use with hospital infection control practices, one would need to know whether cross-immunity develops to different subgroup infections. This question has been addressed by Mufson and colleagues (16), who found that infection with subgroup A strains provided stronger protection from a second infection with the homologous but not the heterologous subgroup. It would also be necessary to perform rapid subgroup diagnosis of nasopharyngeal washings directly on admission, rather than on culture isolates, and this would add a considerable workload to the laboratory. In order to be used as a clinical predictor there would have to be an established consistent difference in disease severity between infections by different subgroups. In two large series to date, subgroup A infection appears more severe $(11,17)$. The authors' limited, retrospective chart review failed to show any such difference, in concordance with the findings of Mufson et al (4). However, the present study did show that there was a greater risk for young children to be infected by subgroup A than subgroup B. At this point, it is not possible to say whether this difference would justify routine subgroup analysis of specimens, since there was no difference in disease severity. This observation may be of importance in estimating the risk of nosocomial infection of RSV in nurseries.

In the authors' analysis using monoclonal antibody subgrouping, there was a striking difference between the two years studied in terms of differing subgroup distribution. The pattern seen for 198788 is in accordance with other studies with both subgroups present but a slight predominance of subgroup A $(2,3,12,13)$. The $1988-89$ season was quite different in being almost exclusively subgroup $\mathrm{B}$. This is a pattern that has recently been described for the 1986-87 season in greater Boston where $89 \%$ of isolates were type B (7). One explanation of the present 1988-89 result could have been that the A subgroup failed to grow from frozen passage material, but this seems unlikely for two reasons. First, no difference was observed in cell susceptibility and isolation time between the subtypes, and in the rare instance where virus recovery was a problem, this appeared related to the cell batch used, success sometimes being achieved by further passage or repeat isolation using a different cell batch. Second, other workers have stated that the B subgroup is the one that replicates more slowly in cell culture, making it unlikely that A would consistently fail to grow (10). Another possible explanation for the appearance of the subgroup B epidemic might be that immunity to subgroup A had gradually built up in the population, allowing spread of subgroup B but not A. The present study showed that only three of $167(2 \%)$ one-month-old or younger infants had positive isolates. This is interesting, since one theory for severe RSV disease in young infants has been immunocomplex formation with circulating maternal antibodies (15). If babies older than one month are more prone to become infected than younger infants, it is unlikely that immune complexes are involved in the pathogenesis of infantile RSV infection, a concept which supports a protective role of maternal antibodies, previously suggested by Parrot et al (18).

This report is, to the authors' knowledge, the first RSV subgroup analysis in Canada, and although contrasting subgroup distribution was found with overwhelming predominance of type B RSV in one season and a higher incidence of subgroup A infection in young age groups, a difference in illness severity in patients infected with the two subgroups was not demonstrated. Therefore, further epidemiological studies are needed to determine the use of routine monoclonal antibody RSV subgrouping in the clinical virology laboratory. 


\section{REFERENCES}

1. Mufson MA, Orvell C, Rafner B, Norrby E. Two distinct subtypes of human respiratory syncytial virus. J Gen Virol 1985;66:2111-24.

2. Anderson LJ, Hierholzer JC, Tsou C, et al. Antigenic characterization of respiratory syncytial virus strains with monoclonal antibodies. J Infect Dis 1985; 151:626-33.

3. Gimenez HB, Hasdmen N, Keir HM, Cash P. Antigenic variation between human respiratory syncytial virus isolates. J Gen Virol 1986;67:863-70.

4. Mufson MA, Belshe RB, Orvell C, Norrby E. Respiratory syncytial virus epidemics: Variable dominance of subgroups A and B strains among children, 1981-1986. J Infect Dis 1987;157:143-8.

5. Hendry RM, Fernie BF, Anderson LJ, McIntosh K. Antigenic and epidemiologic analysis of distinct strains of respiratory syncytial virus from two successive community out-breaks (1983-5). In: Mahy B, Kolakovsky D, eds. The Biology of Negative Strand Viruses. New York: Elsevier Science Publishers, 1987:397-403.

6. Akerlind B, Norrby E. Occurrences of respiratory syncytial virus subtypes A and B strains in Sweden. J Med Virol 1986;19:241-7.

7. Hendry RM, Pierik LT, McIntosh K. Prevalence of RSV subgroups over six consecutive outbreaks: 1981-1987. J Infect Dis 1989;160: 185-90.

8. Tsutsumi H, Onuma M, Suga K, et al. Occurrence of respiratory syncytial virus subgroup A and B strains in Japan 1980 to 1987. J Clin Microbiol 1988;26:1171-4.

9. Akerlind B, Norrby E, Orvell C, Mufson MA. Respiratory syncytial virus: Heterogeneity of subgroup B strains. J Gen Virol 1988;69:2145-54.
10. Morgan LA, Routledge E, Willcocks MM, Samson AC, Scott R, Toms GL. Strain variation of respiratory syncytial virus. J Gen Virol 1987;68:2781-8.

11. Tayler CE, Morrow S, Scott M, Young B, Toms GL. Comparative virulence of respiratory syncytial virus subgroups A and B. Lancet 1989;i:777-8.

12. Orvell C, Norrby E, Mufson MA. Preparation and characterization of monoclonal antibodies directed against five structural components of human respiratory syncytial virus subgroup B. J Gen Virol 1987;68:3125-35.

13. Garcia-Barreno B, Palomo C, Penas C, Delgado T, Perez-Brena P, Melero JA. Marked differences in the antigenic structure of human respiratory syncytial virus $\mathrm{F}$ and $\mathrm{G}$ glycoproteins. J Virol 1989;63:925-32.

14. Stott EJ, Taylor G. Respiratory syncytial virus Brief review. Arch Virol 1985;84:1-52.

15. Welliver RC. Detection, pathogenesis, and therapy of respiratory syncytial virus infections. Clin Microbiol Rev 1988;1:27-39.

16. Mufson MA, Belshe RB, Orvell C, Norrby E. Subgroup characteristics of respiratory syncytial virus strains recovered from children with two consecutive infections. J Clin Microbiol 1987;25:15359.

17. McConnochie KM, Hall CB, Walsh EE, Roghmann KJ. Variation in severity of respiratory syncytial virus infections with subtype. J Pediatr 1990; 1 17:52-62.

18. Parrot RH, Kim HW, Arrobio JO, et al. Epidemiology of respiratory syncytial virus infection in Washington. II. Infection and disease with respect to age, immunologic status, race and sex. Am J Epidemiol 1973;98:289-300. 


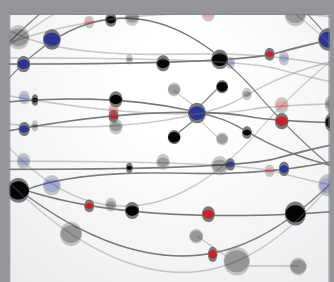

The Scientific World Journal
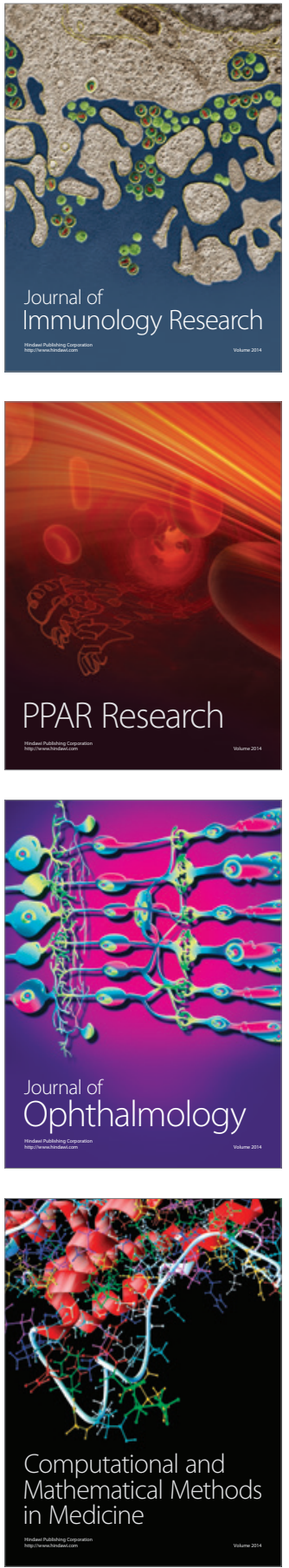

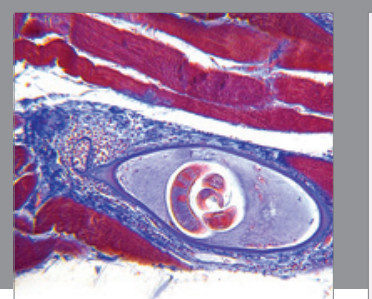

Gastroenterology Research and Practice

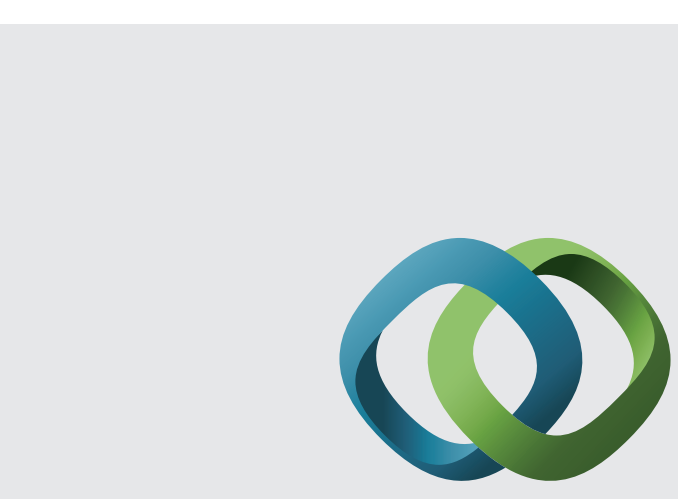

\section{Hindawi}

Submit your manuscripts at

http://www.hindawi.com
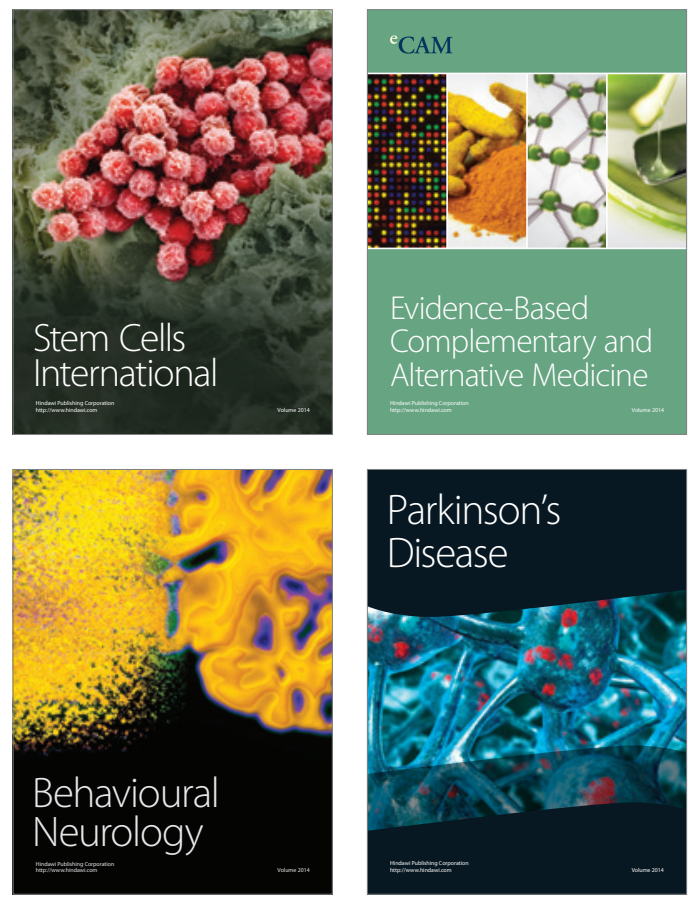
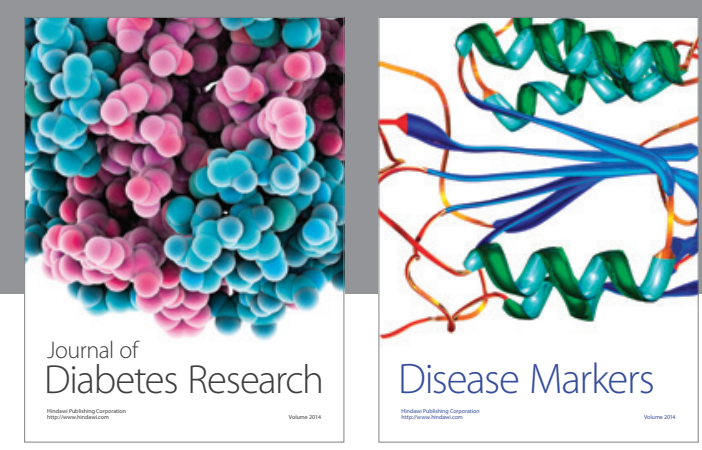

Disease Markers
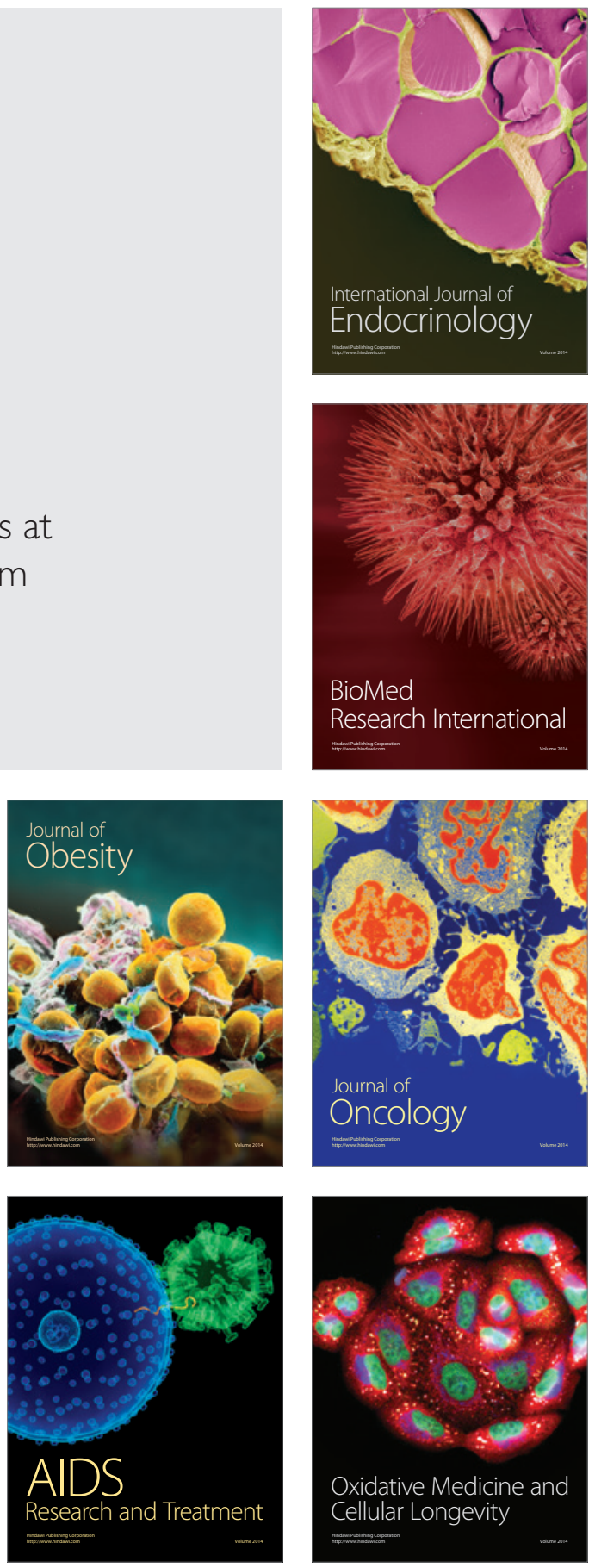